Education

et sociétés

plurilingues

\section{Éducation et sociétés plurilingues}

$43 \mid 2017$

Varia

\title{
Hommage à Marie-Thérèse Weber
}

\section{Comité de lecture d'ESP}

\section{(2) OpenEdition}

Journals

Édition électronique

URL : http://journals.openedition.org/esp/1355

DOI : 10.4000/esp. 1355

ISSN : 2532-0319

\section{Éditeur}

Centre d'Information sur l'Éducation Bilingue et Plurilingue

\section{Édition imprimée}

Date de publication : 1 décembre 2017

Pagination : 6

ISSN : 1127-266X

\section{Référence électronique}

Comité de lecture d'ESP, «Hommage à Marie-Thérèse Weber », Éducation et sociétés plurilingues [En ligne], 43 | 2017, mis en ligne le 01 février 2019, consulté le 24 septembre 2020. URL : http:// journals.openedition.org/esp/1355; DOI : https://doi.org/10.4000/esp.1355 


\section{HOMMAGE À MARIE-THÉRÈSE WEBER}

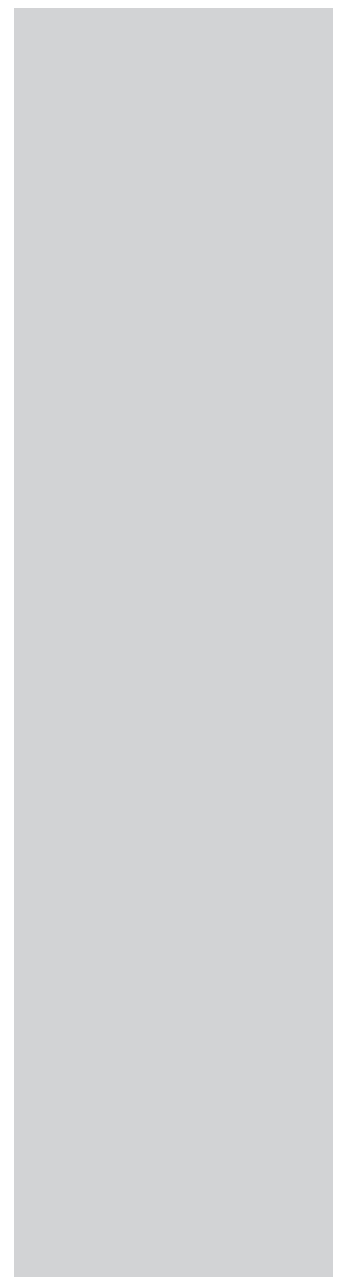

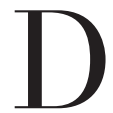
ans ce numéro, l'équipe rédactionnelle d'Éducation et Sociétés Plurilingues se souvient de leur collègue et amie Marie-Thérèse Weber, qui a été une précieuse collaboratrice pendant de longues années. Entre le tout premier numéro (1996) et le $\mathrm{n}^{\circ} 37$ (2014), Marie-Thérèse a contribué vingt-six recensements d'ouvrages, participant ainsi à la diffusion des connaissances sur l'éducation et les sociétés à travers le monde.

En guise d'hommage à son engagement scientifique dans notre effort collectif de promouvoir le bilinguisme et les contacts entre personnes de cultures différentes, nous republions ici le petit article que Marie-Thérèse Weber a publié il y a cinq ans dans $E S P$ «Un exemple de plurilinguisme au quotidien».

Nous publions également le texte d'une de ses amies qui l'a bien connue et qui parle plus intimement de sa vie à Fribourg, de son travail et de ses intérêts. Les membres du comité de lecture se joignent à elle pour souligner sa gentillesse et sa discrétion, ses qualités humaines et professionnelles, en espérant que ce petit témoignage collectif apportera un peu de réconfort à sa sœur et à ses amis en Suisse et ailleurs. 